\title{
Online Appendix
}

\section{Contractual Managerial Incentives with Stock Price Feedback By Tse-Chun Lin, Qi Liu, and Bo Sun}

In this Appendix, we present results that are left out of the paper for brevity. In Section A, we provide a brief review of evidence on the feedback effect. In Section B, we derive the optimal compensation contract in the case of no information production, that is, pay-for-performance $(\hat{\beta})$ and a target investment policy $(\hat{q})$. In Section C, we analyze an alternative information environment in which the speculator's information, when revealed in the market, is noisy. In Section D, we allow for no trading by the liquidity trader. In Section E, we discuss the robustness of our mechanisms, and we also analyze the difference between our mechanisms and those in Holmstrom and Tirole (1993). In Section F, we present additional empirical analysis for Reg SHO as well as using two additional plausibly exogenous shocks to trading frictions, namely, decimalization and Russell 1000/2000 indexing, and we also discuss the potential applications of alternative theories for our empirical results.

\section{A A brief review of evidence on the feedback effect}

The theoretical literature in corporate finance has argued that managers can learn from the information in stock price for their managerial decisions. Prominent examples of this theory include Hayek (1945), Dow and Gorton (1997), Subrahmanyam and Titman (1999), Bond, Goldstein, and Prescott (2010), and Edmans, Goldstein, and Jiang (2015). The key idea is that stock prices aggregate information from many different participants who do not have channels to credibly communicate with the firm outside the trading process. Therefore, stock prices may contain some information that managers do not have.

While the common perception is that managers know more about their firms' operation than outsiders, optimal decisions also depend on external information, such as market demand for a firm's products, the future prospects of the industry, or the potential value of an acquisition target, which outsiders may have better insights into. For example, oil companies heavily rely on external information on oil price forecasts when making investment decisions. More generally, for the feedback effect to be relevant, it only requires that managers do not have complete knowledge and that outside investors have some information that the manager does not have. They need not be more informed than the manager on an absolute basis. A classic example of how information from the stock market can shape real decisions is that after the stock market reacted negatively following a company's announcement of a project, the company's board subsequently rejected 
the proposed project potentially due to the negative market reaction (see Edmans, Goldstein, and Jiang (2015) for detailed discussions and real-life examples).

Previous studies have shown that the feedback effect influences many important corporate policies, including investment (Baker, Stein, and Wurgler (2003); Chen, Goldstein, and Jiang (2007); Bakke and Whited (2010); Foucault and Fresard (2012, 2014)), acquisition (Luo (2005); Edmans, Goldstein, and Jiang (2012)), insider trading (Fishman and Hagerty (1992); Khanna, Slezak, and Bradley (1994)), decisions to seek public financing (Subrahmanyam and Titman (1999)), cross-listing (Foucault and Gehrig (2008), Foucault and Fresard (2012)), capital structure (Fulghieri and Lukin (2001); Chang and Yu (2010)), disclosure policy (Gao and Liang (2013)), and corporate governance (Gorton, Huang, and Kang (2016)). For a more comprehensive review, please see Bond, Edmans, and Goldstein (2012).

\section{B Contracting without information production}

As a benchmark, we analyze the optimal compensation contract in the absence of feedback from stock prices. That is, there is no information production by the speculator: $\theta$ is exogenously set to zero. Shareholders maximize the expected terminal wealth. More specifically, shareholders choose the number of shares $(\hat{\beta})$ that maximizes the expected firm value net of managerial pay. We have characterized the incentive-compatible pay-for-performance in Observation ??. The shareholders' problem is thus reduced to maximizing $(1-\hat{\beta}) V(q)$ subject to $\hat{\beta}=\frac{\delta}{(1-2 \hat{q}) \eta}$. We characterize the equilibrium contract without information production below.

Proposition 1. (Contracting without information production) The optimal contract without information production by the speculator satisfies the following equation:

$$
1-2 \hat{q}-\frac{\delta}{\eta}-\frac{2 \delta\left(\hat{q}-\hat{q}^{2}\right)}{\eta(1-2 \hat{q})^{2}}-\frac{2 \delta V_{0}}{\eta^{2}\left(I_{H}-I_{L}\right)(1-2 \hat{q})^{2}}=0
$$

The optimal managerial incentives $\hat{\beta}$ and corresponding investment strategy $\hat{q}$ are both increasing in the firm's investment opportunities $\left(I_{H}-I_{L}\right)$.

Recall that in the first-best case, as we discussed in Section 3, the optimal policy is $q=1 / 2$. With managerial empire-building incentives, a higher $q$ (toward 1/2) increases the expected compensation, causing the optimal investment policy $(\hat{q})$ to be less than $1 / 2$ in equilibrium.

As in standard contracting theory, optimal managerial incentives in our model increase in response to enlarged investment opportunities. When investment opportunities expand, the investment payoff differential increases, and it is therefore more important to induce desired investment by offering additional incentives. Specifically, when the size differential $\left(I_{H}-I_{L}\right)$ 
increases, the optimal target investment policy $(\hat{q})$ will increase toward the first-best level $(q=$ $1 / 2)$. The pay-for-performance $(\hat{\beta})$ correspondingly increases.

Proof: For brevity, we denote $\Delta=I_{H}-I_{L}$ in the following proof. Without informed trading, the shareholders' objective is to maximize

$$
\left(1-\frac{\delta}{(1-2 q) \eta}\right) \mathcal{V}(q)=\left(1-\frac{\delta}{(1-2 q) \eta}\right)\left[\Delta \eta\left(q-q^{2}\right)+V_{0}\right]
$$

Taking the first-order derivative w.r.t $q$ yields $1-2 q-\frac{\delta}{\eta}-\frac{2 \delta\left(q-q^{2}\right)}{\eta(1-2 q)^{2}}-\frac{2 \delta V_{0}}{\eta^{2} \Delta(1-2 q)^{2}}=0$. Denote the left-hand side of the above equation by $f(q, \Delta)$. Since $f(q, \Delta)=0$, we obtain that $\frac{\partial f}{\partial \Delta}+\frac{\partial f}{\partial q} \frac{\partial q}{\partial \Delta}=0$. Since at the maximum we must have $\frac{\partial f}{\partial q}<0$, the sign of $\frac{\partial q}{\partial \Delta}$ is the same as the sign of $\frac{\partial f}{\partial \Delta}$. Note that $\frac{\partial f}{\partial \Delta}=\frac{2 \delta V_{0}}{\eta^{2} \Delta^{2}(1-2 q)^{2}}>0$, so the optimal policy $\hat{q}$ is increasing in $\Delta$, and thus $\hat{\beta}=\frac{\delta}{(1-2 \hat{q}) \eta}$ is also increasing in $\Delta$.

\section{Model extension: Noisy information}

In the baseline model, we assume that if the speculator is informed (i.e., receives a signal), then the signal will perfectly reveal the future state. As a result, once his information is revealed in the market, all the players will know the future state perfectly. In this section, we extend our model to allow for a noisy signal. Specifically, we assume that if the speculator receives a signal, with probability $k$, the signal is informative and perfectly reveals the future state; with probability $(1-k)$, the signal is uninformative and just purely noisy. No one (including the speculator) can distinguish whether the signal is perfectly informative or just purely noisy. For example, if the speculator receives a positive signal, then he knows that with probability $k$, the future state is good; with probability $1-k$, the signal is noisy and he is actually uninformed about the future state. Meanwhile, if his signal is revealed in the market, all the players also will learn the same information.

Similar to our baseline model, we can show that there exists an equilibrium in which the speculator will submit a buy order if he receives a positive signal, submit a sell order if he receives a negative signal, and not trade if he receives no information. Thus, the speculator's signal will be revealed by the stock price if there are two buy orders or two sell orders; otherwise, his signal is concealed. Moreover, we can calculate that conditional on two buy orders, the manager's updated belief about the probability of good state is $\operatorname{Prob}(\operatorname{good} \mid 2$ buy $)=k+p(1-k)$; conditional on two sell orders, the manager's updated belief about the probability of good state is $\operatorname{Prob}($ good $\mid 2$ sell $)=p(1-k)$. In the other three cases, the speculator's signal is not revealed 
by the stock price, and the manager's belief on the probability of good state is still $p$. In the following analysis, we divide into three cases to solve for this extended model. We take $\theta$ as exogenous for simplicity and show how $\theta$ affects the optimal pay-performance sensitivity. ${ }^{1}$

Case 1: $k>1-q$, where $q$ is the firm's investment policy.

Note that $q<\frac{1}{2}$; thus, in this case, we have $k+p(1-k)>q$ and $p(1-k)<q$ for any $p \in[0,1]$, which implies that the manager will always choose high investment $I_{H}$ in the case of two buy orders and low investment $I_{L}$ in the case of two sell orders. Then we can calculate that the expected firm value is

$$
\begin{aligned}
\mathcal{V}_{F} & =\int_{0}^{1} \frac{p \theta}{2}\left[V_{0}+I_{H} \eta(2(k+p(1-k))-1)\right] d p+\int_{0}^{1} \frac{(1-p) \theta}{2}\left[V_{0}+I_{L} \eta(2 p(1-k)-1)\right] d p \\
& +\left(1-\frac{\theta}{2}\right) \mathcal{V}(q) \\
& =\mathcal{V}(q)+\frac{\left(I_{H}-I_{L}\right) \eta \theta}{2}\left(\frac{k}{3}+\frac{1}{6}-q+q^{2}\right) .
\end{aligned}
$$

Since $\frac{k}{3}+\frac{1}{6}-q+q^{2}>\frac{1}{3}(1-q)+\frac{1}{6}-q+q^{2}>0, \frac{\partial \mathcal{V}_{F}}{\partial \theta}>0$. It is also straightforward to calculate that $\frac{\partial}{\partial \theta}\left(\frac{\partial \mathcal{V}_{F}}{\partial q}\right)=\frac{\left(I_{H}-I_{L}\right) \eta}{2}(-1+2 q)<0$. Note that the shareholders' objective is $\max _{q}(1-\beta) \mathcal{V}_{F}$, where $\beta=\frac{\delta}{(1-2 q) \eta}$. Taking the first-order condition yields that $(1-\beta) \frac{\partial \mathcal{V}_{F}}{\partial q}-\frac{2 \beta}{1-2 q} \mathcal{V}_{F}=0$. Let $G(q, \theta)$ denote the left-hand side of the first-order equation. Since $\left.\frac{\partial G}{\partial q}\right|_{q=q^{*}}<0$, and $\frac{\partial G}{\partial \theta}=$ $(1-\beta) \frac{\partial}{\partial \theta}\left(\frac{\partial \mathcal{V}_{F}}{\partial q}\right)-\frac{2 \beta}{1-2 q} \frac{\partial \mathcal{V}_{F}}{\partial \theta}<0, \frac{\partial q^{*}}{\partial \theta}<0$, and $\frac{\partial \beta^{*}}{\partial \theta}<0$. We summarize the results below.

Proposition 2. Suppose that $k>1-q^{*}$; then, we have
1) $\frac{\partial \mathcal{V}_{F}}{\partial \theta}>0$
2) $\frac{\partial}{\partial \theta}\left(\frac{\partial \mathcal{V}_{F}}{\partial q}\right)<0$
3) $\frac{\partial q^{*}}{\partial \theta}<0$, and $\frac{\partial \beta^{*}}{\partial \theta}<0$.

Case 2: $q \leq k \leq 1-q$.

In this case, we still have $k+p(1-k)>q$ for any $p \in[0,1]$, which implies that the manager will always choose high investment $I_{H}$ in the case of two buy orders. But $p(1-k)<q$ for $p \in\left[0, \frac{q}{1-k}\right)$, and $p(1-k) \geq q$ for $p \in\left[\frac{q}{1-k}, 1\right]$, which implies that the manager will choose low investment $I_{L}$ for $p \in\left[0, \frac{q}{1-k}\right)$ and high investment $I_{H}$ for $p \in\left[\frac{q}{1-k}, 1\right]$ in the case of two sell

\footnotetext{
${ }^{1}$ Recall that in the baseline model, our main point is that the improvement of price informativeness reduces the pay-performance sensitivity (i.e., the substitution effect). Taking $\theta$ exogenous can still deliver the key insight related to our main point.
} 
orders. Then, we can calculate that the expected firm value is

$$
\begin{aligned}
\mathcal{V}_{F} & =\int_{0}^{1} \frac{p \theta}{2}\left[V_{0}+I_{H} \eta(2(k+p(1-k))-1)\right] d p+\int_{0}^{\frac{q}{1-k}} \frac{(1-p) \theta}{2}\left[V_{0}+I_{L} \eta(2 p(1-k)-1)\right] d p \\
& +\int_{\frac{q}{1-k}}^{1} \frac{(1-p) \theta}{2}\left[V_{0}+I_{H} \eta(2 p(1-k)-1)\right] d p+\left(1-\frac{\theta}{2}\right) \mathcal{V}(q) \\
& =\mathcal{V}(q)+\frac{\left(I_{H}-I_{L}\right) \eta \theta}{2} \frac{q}{(1-k)^{2}}\left(k(1-k)(1-q)-\frac{1}{2} q+\frac{2}{3} q^{2}\right) .
\end{aligned}
$$

Since $k(1-k)(1-q)-\frac{1}{2} q+\frac{2}{3} q^{2}>q(1-q)^{2}-\frac{1}{2} q+\frac{2}{3} q^{2}=q\left(\frac{1}{2}-\frac{4}{3} q+q^{2}\right)>0, \frac{\partial \mathcal{V}_{F}}{\partial \theta}>0$. We can also calculate that $\frac{\partial}{\partial \theta}\left(\frac{\partial \mathcal{V}_{F}}{\partial q}\right)=\frac{\left(I_{H}-I_{L}\right) \eta}{2(1-k)^{2}}(k(1-k)-q)(1-2 q)$ is positive if $q<k(1-k)$ and negative if $q>k(1-k)$. As a result, the $\operatorname{sign}$ of $\frac{\partial G}{\partial \theta}$ can be positive when $k(1-k)$ is sufficiently larger than $q$.

Proposition 3. Suppose that $q^{*} \leq k \leq 1-q^{*}$; then, we have 1) $\frac{\partial \mathcal{V}_{F}}{\partial \theta}>0$

2) $\frac{\partial}{\partial \theta}\left(\frac{\partial \mathcal{V}_{F}}{\partial q}\right)<0$ if $q^{*}>k(1-k)$, and $\frac{\partial}{\partial \theta}\left(\frac{\partial \mathcal{V}_{F}}{\partial q}\right)>0$ if $q^{*}<k(1-k)$;

3) there exists $M>0$ such that if $q^{*}+M<k(1-k)$, then $\frac{\partial q^{*}}{\partial \theta}>0$, and $\frac{\partial \beta^{*}}{\partial \theta}>0$.

Case 3: $k<q$.

In this case, we have $k+p(1-k)<q$ for $p \in\left[0, \frac{q-k}{1-k}\right)$, and $k+p(1-k)>q$ for $p \in\left(\frac{q-k}{1-k}, 1\right]$, which implies that the manager will take low investment $I_{L}$ for $p \in\left[0, \frac{q-k}{1-k}\right)$, and high investment $I_{H}$ for $p \in\left[\frac{q-k}{1-k}, 1\right]$ in the case of two buy orders. Similarly, the manager will take low investment $I_{L}$ for $p \in\left[0, \frac{q}{1-k}\right)$, and high investment $I_{H}$ for $p \in\left[\frac{q}{1-k}, 1\right]$ in the case of two sell orders. Then we can calculate that the expected firm value is

$$
\begin{aligned}
\mathcal{V}_{F} & =\int_{0}^{\frac{q-k}{1-k}} \frac{p \theta}{2}\left[V_{0}+I_{L} \eta(2(k+p(1-k))-1)\right] d p+\int_{\frac{q-k}{1-k}}^{1} \frac{p \theta}{2}\left[V_{0}+I_{H} \eta(2(k+p(1-k))-1)\right] d p \\
& +\int_{0}^{\frac{q}{1-k}} \frac{(1-p) \theta}{2}\left[V_{0}+I_{L} \eta(2 p(1-k)-1)\right] d p+\int_{\frac{q}{1-k}}^{1} \frac{(1-p) \theta}{2}\left[V_{0}+I_{H} \eta(2 p(1-k)-1)\right] d p \\
& +\left(1-\frac{\theta}{2}\right) \mathcal{V}(q) \\
& =\mathcal{V}(q)+\frac{\left(I_{H}-I_{L}\right) \eta \theta}{2} \frac{k^{2}}{(1-k)^{2}}\left(\frac{1}{2}-\frac{1}{3} k-q+q^{2}\right) .
\end{aligned}
$$

Since $\frac{1}{2}-\frac{1}{3} k-q+q^{2}>\frac{1}{2}-\frac{1}{3} q-q+q^{2}>0, \frac{\partial \mathcal{V}_{F}}{\partial \theta}>0$. We can also calculate that $\frac{\partial}{\partial \theta}\left(\frac{\partial \mathcal{V}_{F}}{\partial q}\right)=$ $\frac{\left(I_{H}-I_{L}\right) \eta k^{2}}{2(1-k)^{2}}(-1+2 q)<0$. Thus, $\frac{\partial G}{\partial \theta}<0$, which implies that $\frac{\partial q^{*}}{\partial \theta}<0$ and $\frac{\partial \beta^{*}}{\partial \theta}<0$. We formalize the results below. 
Proposition 4. Suppose that $k<q^{*}$; then, we have

1) $\frac{\partial \mathcal{V}_{F}}{\partial \theta}>0$

2) $\frac{\partial}{\partial \theta}\left(\frac{\partial \mathcal{V}_{F}}{\partial q}\right)<0$

3) $\frac{\partial q^{*}}{\partial \theta}<0$, and $\frac{\partial \beta^{*}}{\partial \theta}<0$.

From the analysis above, we can see that in most cases, due to the feedback effect, information revealed by the stock price has a substitution effect for the firm's internal investment policy, and thus reduces the pay-performance sensitivity. Only when $k$ is moderate and $q^{*}$ is very small can information revealed in the market increase pay-for-performance in managerial compensation. To see why, consider the following scenario. Suppose there are two buy orders in the market. The manager's own private information $p$ lies between 0 and $q$, and his updated belief about the probability of a good state is increased to a number between $q$ and $\frac{1}{2}$. In this particular case, the manager will take low investment without the information from the market, but he will take high investment with the information from the market. High investment reduces the firm value in this case because the updated belief on the probability of good state is still below $\frac{1}{2}$. Such a scenario will happen only if $\max \left(0, \frac{q^{*}-k}{1-k}\right)<p<\min \left(q^{*}, \frac{1}{2}-k\right) \cdot{ }^{2}$ Under a restrictive circumstance involving very severe agency friction (a very small $q^{*}$ ), additional, yet inadequate, information from prices can push the manager's updated belief into a particular, restricted range that induces undesired managerial action, thereby necessitating stronger-powered pay. In most cases, information in stock price substitutes out direct incentives in CEO pay, even when information is noisy.

\section{Model extension: Liquidity trader}

In the baseline model, we assume that the liquidity trader will submit either a buy order or a sell order with equal probability. Thus, if the total order flow is $X=-1$ or 1 , it is clear that such a buy or sell order is submitted by the liquidity trader, and it also implies that the speculator receives no information and does not trade.

In this appendix, we extend the liquidity trader's trading behavior by assuming that he can submit an order $z_{l} \in\{-1,0,1\}$ with probability $\frac{1}{3}$ for each possible order. In this case, the possible order flows are $X \in\{-2,-1,0,1,2\}$. Similar to our baseline model, we can show that

\footnotetext{
${ }^{2}$ Similarly, in the case of two buy orders, the firm value can be hurt by the revealed information in the following scenario: the manager's updated belief about the probability of good state is decreased to a number between $q$ and $\frac{1}{2}$. In this scenario, the manager will always take high investment; i.e., the information revealed in the market does not change his investment decision. But the manager would take low investment if the first-best investment policy can be implemented because the updated belief on the probability of good state is below $\frac{1}{2}$. Such a scenario will happen only if $\min \left(1, \frac{q^{*}}{1-k}\right)<p<\min \left(1, \frac{1}{2(1-k)}\right)$.
} 
there exists an equilibrium in which the speculator will submit a buy order if he receives a positive signal, a sell order if he receives a negative signal, and no trade if he receives nothing. The difference from the baseline model is that if the order flow is $X=-1$ or 1 , such a buy or sell order can come from either the speculator or the liquidity trader. In this case, as it is possible that it is an order from the speculator, the manager will update his belief to some extent. Based on the mechanism similar to that in the case where the speculator has noisy information (illustrated in Appendix C), we show below that our results broadly hold except for under very restrictive conditions.

We take $\theta$ as exogenous for simplicity and show how $\theta$ affects the optimal pay-performance sensitivity. If the total order flow is $X=1$, then different from the baseline model, such a buy order can come from the speculator with probability $\frac{1}{3} p \theta$, or from the liquidity trader with probability $\frac{1}{3}(1-\theta)$. Thus, the manager's updated belief about the probability of good state is $\operatorname{Prob}(\operatorname{good} \mid X=1)=\frac{p \theta}{p \theta+(1-\theta)}+\frac{1-\theta}{p \theta+(1-\theta)} p=\frac{p}{p \theta+(1-\theta)}>p$. Similarly, if the total order flow is $X=-1$, such a sell order can come from the speculator with probability $\frac{1}{3}(1-p) \theta$, or from the liquidity trader with probability $\frac{1}{3}(1-\theta)$. Thus, the manager's updated belief about the probability of good state is $\operatorname{Prob}(\operatorname{good} \mid X=-1)=\frac{1-\theta}{(1-p) \theta+(1-\theta)} p<p$. The other cases of $X=\{-2,0,2\}$ are the same as in the baseline model. Thus, we have the following table:

\begin{tabular}{|l|l|l|}
\hline Order flow & Probability of the event & Manager's updated belief \\
\hline 2 buys & $\frac{1}{3} p \theta$ & 1 \\
\hline 1 buy 1 sell & $\frac{1}{3} \theta$ & $p$ \\
\hline 2 sells & $\frac{1}{3}(1-p) \theta$ & 0 \\
\hline none & $\frac{1}{3}(1-\theta)$ & $p$ \\
\hline 1 buy & $\frac{1}{3}(p \theta+1-\theta)$ & $\frac{p}{p \theta+(1-\theta)}$ \\
\hline 1 sell & $\frac{1}{3}(1-p \theta)$ & $\frac{p(1-\theta)}{(1-p) \theta+(1-\theta)}$ \\
\hline
\end{tabular}

Taking the above possible cases into account, we can calculate the expected firm value in the 
presence of feedback as the following:

$$
\begin{aligned}
\mathcal{V}_{F}(q, \theta)= & \int_{0}^{\frac{q(1-\theta)}{1-q \theta}} \frac{1}{3}(p \theta+1-\theta) I_{L} \eta\left[\frac{2 p}{p \theta+(1-\theta)}-1\right] d p \\
& +\int_{\frac{q(1-\theta)}{1-q \theta}}^{1} \frac{1}{3}(p \theta+1-\theta) I_{H} \eta\left[\frac{2 p}{p \theta+(1-\theta)}-1\right] d p \\
& +\int_{0}^{\frac{q}{1-\theta+q \theta}} \frac{1}{3}(1-p \theta) I_{L} \eta\left[\frac{2 p(1-\theta)}{(1-p) \theta+(1-\theta)}-1\right] d p \\
& +\int_{\frac{q}{1-\theta+q \theta}}^{1} \frac{1}{3}(1-p \theta) I_{H} \eta\left[\frac{2 p(1-\theta)}{(1-p) \theta+(1-\theta)}-1\right] d p \\
& +\frac{1}{3}(1-\theta)\left(I_{H}-I_{L}\right) \eta\left(q-q^{2}\right)+\frac{1}{3} \theta\left(I_{H}-I_{L}\right) \eta\left(q-q^{2}\right) \\
& +\frac{1}{6} \theta I_{H} \eta-\frac{1}{6} \theta I_{L} \eta+V_{0} \\
& \frac{1}{3}\left(I_{H}-I_{L}\right) \eta \frac{1-q}{1-\theta q}\left[\frac{\theta(1-q)}{2(1-\theta q)}+\frac{q(1-\theta)}{1-\theta q}\right] \\
& +\frac{1}{3}\left(I_{H}-I_{L}\right) \eta\left[1-\frac{q}{1-\theta+\theta q}\right]\left[\frac{q}{1-\theta+\theta q}-\frac{\theta}{2}\left(1+\frac{q}{1-\theta+\theta q}\right)\right] \\
& +\frac{1}{3}\left(I_{H}-I_{L}\right) \eta\left(q-q^{2}\right)+\frac{1}{6}\left(I_{H}-I_{L}\right) \eta \theta+V_{0} .
\end{aligned}
$$

The shareholders' objective is $\max _{q}(1-\beta) \mathcal{V}_{F}$, where $\beta=\frac{\delta}{(1-2 q) \eta}$. Taking the first-order condition yields that $(1-\beta) \frac{\partial \mathcal{V}_{F}}{\partial q}-\frac{2 \beta}{1-2 q} \mathcal{V}_{F}=0$. Let $G(q, \theta)$ denote the left-hand side of the first-order equation. Since $\left.\frac{\partial G}{\partial q}\right|_{q=q^{*}}<0$, if $\frac{\partial G}{\partial \theta}=(1-\beta) \frac{\partial}{\partial \theta}\left(\frac{\partial \mathcal{V}_{F}}{\partial q}\right)-\frac{2 \beta}{1-2 q} \frac{\partial \mathcal{V}_{F}}{\partial \theta}<0$, then $\frac{\partial q^{*}}{\partial \theta}<0$ and $\frac{\partial \beta^{*}}{\partial \theta}<0$. We can show that information in stock prices has a substitution effect on pay-for-performance except for under very restrictive conditions, formalized below.

Proposition 5. Suppose that the liquidity trader can submit an order $z_{l} \in\{-1,0,1\}$ with probability $\frac{1}{3}$ for each possible order.

(1) $\frac{\partial \mathcal{V}_{F}}{\partial \theta}>0$;

(2) $\frac{\partial}{\partial \theta}\left(\frac{\partial \mathcal{V}_{F}}{\partial q}\right)<0$ if $q>\frac{1-\theta}{3-\theta}$; If $\theta>1-\left(\frac{1}{2}\right)^{1 / 3}$, then when $q$ is close to 0 , $\frac{\partial}{\partial \theta}\left(\frac{\partial \mathcal{V}_{F}}{\partial q}\right)>0$.

(3) $\frac{\partial \beta^{*}}{\partial \theta}<0$ if $q^{*}>\frac{1-\theta}{3-\theta}$; If $\theta>1-\left(\frac{1}{2}\right)^{1 / 3}$, then there exists $q_{0}\left(<\frac{1}{3}\right)$ such that when $q^{*}<q_{0}$, $\frac{\partial \beta^{*}}{\partial \theta}>0$.

Proof. (1) Let $Y=\frac{1-q}{1-\theta q}\left[\frac{\theta(1-q)}{1-\theta q}+\frac{2 q(1-\theta)}{1-\theta q}\right]+\left[1-\frac{q}{1-\theta+\theta q}\right]\left[\frac{2 q}{1-\theta+\theta q}-\theta\left(1+\frac{q}{1-\theta+\theta q}\right)\right]+2\left(q-q^{2}\right)+\theta$, 
then $\mathcal{V}_{F}=\frac{1}{6}\left(I_{H}-I_{L}\right) \eta Y+V_{0}$. We can calculate that

$$
\begin{aligned}
\frac{\partial Y}{\partial \theta}= & \frac{q(1-q)}{(1-\theta q)^{2}}\left[\frac{\theta(1-q)}{1-\theta q}+\frac{2 q(1-\theta)}{1-\theta q}\right] \\
& +\frac{1-q}{1-\theta q}\left[\frac{1-q}{1-\theta q}+\frac{\theta q(1-q)}{(1-\theta q)^{2}}+\frac{2 q^{2}(1-\theta)}{(1-\theta q)^{2}}-\frac{2 q}{1-\theta q}\right] \\
& -\frac{q(1-q)}{(1-\theta+\theta q)^{2}}\left[\frac{2 q}{1-\theta+\theta q}-\theta\left(1+\frac{q}{1-\theta+\theta q}\right)\right] \\
& +\left[1-\frac{q}{1-\theta+\theta q}\right]\left[\frac{2 q(1-q)}{(1-\theta+\theta q)^{2}}-\left(1+\frac{q}{1-\theta+\theta q}\right)-\frac{\theta q(1-q)}{(1-\theta+\theta q)^{2}}\right]+1 \\
= & \frac{1-q}{(1-\theta q)^{3}}\left[1+(\theta-3) q+(4-3 \theta) q^{2}\right] \\
& +\frac{1}{(1-\theta+\theta q)^{3}}\left[q\left(2-5 q+4 q^{2}\right)-\theta q\left(2-5 q+3 q^{2}\right)\right] .
\end{aligned}
$$

Since $(\theta-3)^{2}-4(4-3 \theta)<0,1+(\theta-3) q+(4-3 \theta) q^{2}>0$. It is also straightforward to see that $q\left(2-5 q+4 q^{2}\right)-\theta q\left(2-5 q+3 q^{2}\right)>q\left(2-5 q+4 q^{2}\right)-\theta q\left(2-5 q+4 q^{2}\right)=(1-\theta) q\left(2-5 q+4 q^{2}\right)>0$. Therefore, $\frac{\partial Y}{\partial \theta}>0$, which implies that $\frac{\partial \mathcal{V}_{F}}{\partial \theta}>0$.

(2) Since $\frac{\partial}{\partial \theta}\left(\frac{\partial \mathcal{V}_{F}}{\partial q}\right)=\frac{1}{6}\left(I_{H}-I_{L}\right) \eta \frac{\partial}{\partial \theta}\left(\frac{\partial Y}{\partial q}\right)=\frac{1}{6}\left(I_{H}-I_{L}\right) \eta \frac{\partial}{\partial q}\left(\frac{\partial Y}{\partial \theta}\right)$, based on the derivation of $\frac{\partial Y}{\partial \theta}$ in part $(1)$ of this proof, we can calculate that

$$
\frac{\partial}{\partial q}\left(\frac{\partial Y}{\partial \theta}\right)=-\frac{2(1-\theta)(1-2 q)[2+(\theta-3) q]}{(1-\theta q)^{4}}+\frac{2(1-\theta)(1-2 q)[(1-\theta)-(3-\theta) q]}{(1-\theta+\theta q)^{4}} .
$$

It is easy to see that if $q>\frac{1-\theta}{3-\theta}, \frac{\partial}{\partial q}\left(\frac{\partial Y}{\partial \theta}\right)<0$, and so $\frac{\partial}{\partial \theta}\left(\frac{\partial \mathcal{V}_{F}}{\partial q}\right)<0$.

If $q$ goes to zero, $\frac{\partial}{\partial q}\left(\frac{\partial Y}{\partial \theta}\right)$ approaches to $\frac{2}{(1-\theta)^{2}}-4(1-\theta)>0$ if $\theta>1-\left(\frac{1}{2}\right)^{1 / 3}$.

(3) Since $\frac{\partial \beta^{*}}{\partial \theta}<0$ if and only if $(1-\beta) \frac{\partial}{\partial \theta}\left(\frac{\partial \mathcal{V}_{F}}{\partial q}\right)-\frac{2 \beta}{1-2 q} \frac{\partial \mathcal{V}_{F}}{\partial \theta}<0$, and note that as $q$ goes to zero, $\beta$ also goes to zero, together with part (1) and (2) of this proposition, it implies that $\frac{\partial \beta^{*}}{\partial \theta}<0$ if $q^{*}>\frac{1-\theta}{3-\theta}$; if $\theta>1-\left(\frac{1}{2}\right)^{1 / 3}$, then there exists $q_{0}\left(<\frac{1}{3}\right)$ such that when $q^{*}<q_{0}, \frac{\partial \beta^{*}}{\partial \theta}>0$.

Under a restrictive circumstance involving very severe agency friction (a very small $q^{*}$ ), additional, yet inadequate, information from prices can push the manager's updated belief into a particular, restricted range that induces undesired managerial action, necessitating strongerpowered pay (see Appendix $\mathrm{C}$ for details on the mechanism). In most cases, information in stock price substitutes out direct incentives in CEO pay. 


\section{E Robustness of model implication}

\section{E.1 Key model features}

This subsection discusses which of the model's features are necessary for its key contracting results. In substance, there are three essential features in the model. First, managers learn new information from the stock prices and use that to guide their real decisions, that is, the feedback effect exists. Second, there are agency frictions present in managerial decisions. Third, market speculators' information acquisition responds to managerial pay. Our mechanisms, sufficiently produced by the first two elements and amplified by the third, are robust to various modifications of model assumptions.

The first two building blocks - the feedback effect and agency frictions related to real decisions - are sufficient in delivering a substitution relationship between incentive contracting and information production in the stock market: when the market can aggregate and reveal more information, it makes the linkage between managerial actions and resulting outcomes more certain to managers ex ante, which guides their real decisions and helps correct managerial bias, rendering incentive pay less necessary. This mechanism is not specific to any particular agency friction.

To model agency frictions, the current model features empire-building motives on the part of managers, which can be generalized to include various other agency conflicts related to real decisions. For example, an alternative version of the model could incorporate quiet-life managers — as suggested in Hicks (1935) and Bertrand and Mullainathan (2003), among others - who may prefer to avoid the difficult decisions and costly efforts associated with shutting down old plants. An extension of the current model may allow for managers to exert effort to improve their own signals and actively learn about the state. The main intuition of our mechanisms information provision by the market guides managers in their real decisions and thus substitutes out direct incentive provision in contracting - is robust to these alternative agency frictions.

The last element, which features an endogenous response of speculators' information acquisition to pay, further amplifies the effects of stock market conditions on pay. Anticipating a more uncertain firm payoff under a weak-powered pay regime, market speculators rationally produce more information in response to the increased return from their learning. Therefore, shareholders have less incentive to use high-powered compensation, which deters information production in the market. Our model implications do not hinge on this endogenous response of speculators and are robust to leaving information production exogenous (Observation ??). 


\section{E.2 Substitution vs complementarity}

The monitoring role of stock markets highlighted in Holmstrom and Tirole (1993) suggests that equity compensation is more effective in offering incentives when stock prices incorporate more information about managerial actions, predicting a complementary relationship between incentive pay and market informativeness, which is the opposite of what we find. We would like to make clear the difference in the mechanisms in our analysis and those illustrated in Holmstrom and Tirole (1993).

In Holmstrom and Tirole (1993), when price efficiency increases, the stock price provides a less noisy signal of managerial performance (effort). Thus, if the manager is risk averse, it is optimal to increase the weighting of the contract on the stock price relative to non-price measures of performance, such as accounting profits. Simply put, shareholders pay the manager according to the stock price (more), given that it reflects managerial effort (more); that is, there is a complementary relationship. This is rather different from what we model in this paper, which is that the manager learns from stock prices and uses the new information to guide his real decisions; stock market information clarifies the consequences of managerial actions to managers, and reduces uncertainty about future outcomes and associated rewards, helping prevent managers from engaging in harmful activities. Market information thus substitutes out the necessity to pay monetary incentives.

To further distinguish the two mechanisms, it is worth noting that Holmstrom and Tirole (1993) study forecasting price efficiency (FPE), which describes whether the price of a given security accurately reflects managerial actions and thus predicts the future value of the security (following the terminology in Bond, Edmans, and Goldstein (2012)); while we study revelatory price efficiency (RPE), which reflects the extent to which prices reveal the information necessary for real efficiency. As pointed out in Bond, Edmans, and Goldstein (2012), while RPE immediately generates real efficiency (i.e., the feedback effect), it is quite possible for prices to be efficient in the forecasting sense but does not affect real efficiency. The different form of price efficiency delivers different contracting outcomes in Holstrom and Tirole (1993) and our model.

One could also be concerned about whether our results are an artifact of a binary investment and/or risk-neutrality on the part of the manager. Now we show that our results hold when the manager's decision is continuous. Suppose that the manager is allowed to make a continuous investment decision between $I_{L}$ and $I_{H}$ in our model, where $I_{L}$ and $I_{H}$ can take any value. We first show that the manager will choose either the highest investment or the lowest investment (which can be zero or negative). The proof is as follows. Let $y$ be the manager's updated belief on the probability of a good state (in our model, $y$ could equal $p, 0$, or 1 ). If the manager chooses the investment level $I \in\left[I_{L}, I_{H}\right]$, then his expected payoff is $\beta E[V]+\delta I=\beta V_{0}+\beta \eta I(2 y-1)+\delta I$, which is linear in $I$. Thus, the manager's optimal choice will be $I_{L}$ if $\beta \eta(2 y-1)+\delta<0$, or $I_{H}$ 
if $\beta \eta(2 y-1)+\delta \geq 0$. With the same threshold property as in the binary case, i.e., the manager takes the highest investment if and only if $y$ is as large as a threshold, the rest of the proof in the paper immediately follows.

In the proof above, the feature that the manager's expected payoff is linear in the investment is based on the assumption that the manager is risk-neutral. Yet the main results are robust with regard to the manager's risk preferences. When the manager is risk averse, we can still show that 1) price informativeness increases firm value, and 2) the pay-performance sensitivity is reduced with feedback. The proof is as follows.

Assume that the manager is risk-averse with a utility function $u$, where $u^{\prime}(\cdot)>0$ and $u^{\prime \prime}(\cdot)<0$. Let $y$ be the manager's updated belief on the probability of a good state. Then it still holds true that the manager will take $I_{H}$ if he learns good information from the market, and $I_{L}$ if he learns bad information from the market. In the case where he does not learn information from the market, $y=p$ holds, and his expected payoff is $E[u]=p u\left(\beta\left(V_{0}+I \eta\right)+\delta I\right)+(1-p) u\left(\beta\left(V_{0}-\right.\right.$ $I \eta)+\delta I$, where $\beta$ is the pay-performance sensitivity. To maximize his own expected utility, the manager will take $I^{*}(\beta, p)=\arg \max _{I} E[u]$. The expected firm value in this case with no learning is $\mathcal{V}(\beta)=V_{0}+\int_{0}^{1} I^{*}(\beta, p)[\eta p+(-\eta)(1-p)] d p=V_{0}+Y(\beta)$. Given the amount of information production $(\theta)$, we can derive the expected firm value with feedback as

$$
\begin{aligned}
\mathcal{V}_{F}(\beta, \theta) & =E\left[\frac{p \theta}{2}\left(V_{0}+I_{H} \eta\right)+\frac{(1-p) \theta}{2}\left(V_{0}-I_{L} \eta\right)+\left(1-\frac{\theta}{2}\right) \mathcal{V}(\beta)\right] \\
& =\mathcal{V}(\beta)+\frac{\theta\left(I_{H}-I_{L}\right) \eta}{2}\left(\frac{1}{2}-\frac{2 Y(\beta)}{\left(I_{H}-I_{L}\right) \eta}\right)
\end{aligned}
$$

Recall that under the first-best strategy, the expected firm value equals $V_{0}+\frac{1}{4}\left(I_{H}-I_{L}\right) \eta$. Thus, $Y(\beta)<\frac{1}{4}\left(I_{H}-I_{L}\right) \eta$ holds, which implies that $\frac{1}{2}-\frac{2 Y(\beta)}{\left(I_{H}-I_{L}\right) \eta}>0$. Thus, $\frac{\partial \mathcal{V}_{F}}{\partial \theta}>0$ : Firm value is increasing in market information.

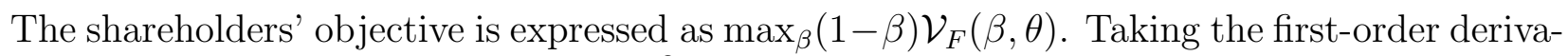
tive with respect to $\beta$ yields $-\mathcal{V}_{F}+(1-\beta) \frac{\partial \mathcal{V}_{F}}{\partial \beta}=0$. By the Implicit Function Theorem, it is easy to derive that as long as $\frac{\partial}{\partial \theta}\left(\frac{\partial \mathcal{V}_{F}}{\partial \beta}\right)<0, \frac{\partial \beta}{\partial \theta}<0$ holds: if market information $(\theta)$ and incentive compensation $(\beta)$ are strategic substitutes, feedback will lower optimal pay-for-performance. Now we show that $\frac{\partial}{\partial \theta}\left(\frac{\partial \mathcal{V}_{F}}{\partial \beta}\right)<0$ holds. Since $\frac{\partial}{\partial \theta}\left(\frac{\partial \mathcal{V}_{F}}{\partial \beta}\right)=-\frac{\partial Y(\beta)}{\partial \beta}=-\frac{\partial \mathcal{V}(\beta)}{\partial \beta}$, we have our main result that the pay-performance sensitivity is reduced with feedback as long as the condition $\left.\frac{\partial \mathcal{V}(\beta)}{\partial \beta}\right|_{\beta=\beta^{*}}>0$ is satisfied. Note that the optimal pay-performance sensitivity without feedback, denoted by $\hat{\beta}$, satisfies that $(1-\beta) \frac{\partial \mathcal{V}(\beta)}{\partial \beta}-\mathcal{V}(\beta)=0$, which implies that $\left.\frac{\partial \mathcal{V}(\beta)}{\partial \beta}\right|_{\beta=\hat{\beta}}>0$. Therefore, we have $\frac{\partial}{\partial \theta}\left(\frac{\partial \mathcal{V}_{F}}{\partial \beta}\right)<0$ and $\frac{\partial \beta}{\partial \theta}<0$, and thus the optimal pay-for-performance with 
Table 1: The effects of Reg SHO on stock volatility

This table presents the effects of Reg SHO on stock return volatility. tvol is total volatility, measured as the standard deviation of daily stock returns. ivol is idiosyncratic volatility based on Fama-French 3-factor model. Definitions of the other variables are in Table ??. Standard errors are clustered at the firm level and reported in parentheses. ${ }^{*}, * *$, and ${ }^{* * *}$ represent statistical significance at the $10 \%, 5 \%$, and $1 \%$ levels, respectively.

\begin{tabular}{|c|c|c|c|c|c|c|c|c|}
\hline & \multicolumn{4}{|c|}{ Contract Change } & \multicolumn{4}{|c|}{ No Contract Change } \\
\hline & tvol & tvol & ivol & ivol & tvol & tvol & ivol & ivol \\
\hline $\mathbb{1}^{\text {Pilot }} \times \mathbb{1}^{\text {During }}$ & $\begin{array}{c}-0.322 \\
(0.719)\end{array}$ & $\begin{array}{c}0.335 \\
(0.575)\end{array}$ & $\begin{array}{c}-0.136 \\
(0.592)\end{array}$ & $\begin{array}{c}0.322 \\
(0.505)\end{array}$ & $\begin{array}{c}1.152 \\
(0.766)\end{array}$ & $\begin{array}{c}0.803 \\
(0.731)\end{array}$ & $\begin{array}{c}0.792 \\
(0.653)\end{array}$ & $\begin{array}{c}0.454 \\
(0.668)\end{array}$ \\
\hline Size & & $3.192 * * *$ & & $2.053^{* * *}$ & & $3.386^{* * * *}$ & & $2.303^{* * *}$ \\
\hline $\mathrm{Q}$ & & $\begin{array}{c}(0.816) \\
0.970 * * *\end{array}$ & & $\begin{array}{c}(0.701) \\
0.493 * * *\end{array}$ & & $\begin{array}{c}(0.843) \\
1.039^{* * *}\end{array}$ & & $\begin{array}{c}(0.731) \\
0.570^{* * *}\end{array}$ \\
\hline & & $(0.251)$ & & $(0.155)$ & & $(0.197)$ & & $(0.114)$ \\
\hline Leverage & & $\begin{array}{c}0.023 \\
(0.032)\end{array}$ & & $\begin{array}{c}-0.007 \\
(0.026)\end{array}$ & & $\begin{array}{c}-0.057^{* *} \\
(0.025)\end{array}$ & & $-0.048^{* *}$ \\
\hline Dividend & & $\begin{array}{l}1.459^{*} \\
(0.760)\end{array}$ & & $\begin{array}{c}(0.026) \\
1.698^{* *} \\
(0.729)\end{array}$ & & $\begin{array}{l}(0.025) \\
1.537^{*} \\
(0.819)\end{array}$ & & $\begin{array}{l}(0.021) \\
1.778^{* *} \\
(0.788)\end{array}$ \\
\hline Age & & $\begin{array}{c}-1.421^{* * *} \\
(0.142)\end{array}$ & & $\begin{array}{c}-1.323^{* * *} \\
(0.120)\end{array}$ & & $\begin{array}{c}-1.413^{* * *} \\
(0.147)\end{array}$ & & $\begin{array}{c}-1.325^{* * *} \\
(0.124)\end{array}$ \\
\hline IOR & & $-5.698^{* * *}$ & & $-6.945^{* * *}$ & & $-5.692^{* * *}$ & & $-6.832^{* * *}$ \\
\hline Cash & & $\begin{array}{l}-3.874 \\
(8.367)\end{array}$ & & $\begin{array}{c}-2.013 \\
(7.976)\end{array}$ & & $\begin{array}{l}-4.170 \\
(8.130)\end{array}$ & & $\begin{array}{c}-2.663 \\
(7.786)\end{array}$ \\
\hline INV & & $\begin{array}{c}7.853^{* * *} \\
(1.666)\end{array}$ & & $\begin{array}{c}4.907^{* * *} \\
(1.429)\end{array}$ & & $\begin{array}{c}4.334^{* * *} \\
(1.616)\end{array}$ & & $\begin{array}{c}2.762^{* *} \\
(1.097)\end{array}$ \\
\hline IOC & & $\begin{array}{l}5.236^{*} \\
(3.112)\end{array}$ & & $\begin{array}{l}6.794^{* *} \\
(2.869)\end{array}$ & & $\begin{array}{l}5.886^{*} \\
(3.333)\end{array}$ & & $\begin{array}{c}6.726^{* *} \\
(3.089)\end{array}$ \\
\hline RetStd & & $\begin{array}{c}39.359^{* * *} \\
(5.206)\end{array}$ & & $\begin{array}{c}31.044^{* * * *} \\
(4.421)\end{array}$ & & $\begin{array}{c}41.083^{* * *} \\
(5.194)\end{array}$ & & $\begin{array}{c}31.815^{* * *} \\
(4.472)\end{array}$ \\
\hline Year Dummies & $\mathrm{Y}$ & $\mathrm{Y}$ & $\mathrm{Y}$ & $\mathrm{Y}$ & $\mathrm{Y}$ & $\mathrm{Y}$ & $\mathrm{Y}$ & $\mathrm{Y}$ \\
\hline Firm Dummies & Y & Y & Y & Y & $\mathrm{Y}$ & $\mathrm{Y}$ & $\mathrm{Y}$ & $\mathrm{Y}$ \\
\hline No. of Obs & 7,751 & 6,500 & 7,751 & 6,500 & 7,643 & 6,325 & 7,643 & 6,325 \\
\hline R-squared & 0.760 & 0.814 & 0.758 & 0.803 & 0.758 & 0.810 & 0.757 & 0.799 \\
\hline
\end{tabular}

the feedback effect, denoted by $\beta^{*}$, is lower than without it: $\beta^{*}<\hat{\beta}$ when $\theta>0\left(\beta^{*}=\hat{\beta}\right.$ when $\theta=0)$.

\section{F Additional empirical analysis}

\section{F.1 Pilot firms' decision to change compensation policy}

To further gauge the role of stock volatility in accounting for the CEO compensation changes during Reg SHO, we re-run Equation (??) specification for only the contract-change group, retaining the non-pilot firms as the control firms. The pilot firms that made tangible changes in contract terms exhibited no significant changes in volatility, as shown in the first panel of Table 1. We find similar results for the no-contract-change group (the second panel of Table 1). Together with our full-sample result (Table 4) as well as the finding in Diether, Lee, and Werner (2009) that daily volatility is unaffected, there is no evidence that supports a risk-sharing view.

To better understand firms' decision to adopt compensation policy changes, we perform the following logit regression:

$$
\mathbb{1}_{i, t}^{\text {ContractChange }}=a_{i}+a_{t}+a_{1} \cdot \text { fric }_{i, t-1}+a_{2} \cdot \operatorname{vol}_{i, t-1}+a_{3} \cdot X_{i, t-1}+\epsilon_{i, t},
$$


Table 2: Market frictions, volatility, and CEO contract changes

This table presents the relations between market frictions, volatility, and firms' decision to change compensation policy during Reg SHO, using the logit regression. The sample is from 2005 to 2007. ContractChange is a dummy variable that equals one if the firm is changing the CEO contract in that year, and zero otherwise. effcost is the effective trading cost (Hasbrouck (2009)). spread is the bid-ask spread. tvol is the total volatility calculated using daily returns. ivol is the idiosyncratic volatility calculated as the residuals from Fama-French 3-factor regression (Ang et al. (2006)). All the other variables are defined in Table ??. All regressions are controlled for firm and year fixed effects. Standard errors are clustered at the firm level and reported in the parenthesis. *, **, and $* * *$ represent statistical significance at the $10 \%, 5 \%$, and $1 \%$ levels, respectively.

\begin{tabular}{|c|c|c|c|c|}
\hline & $\mathbb{1}^{\text {ContractChange }}$ & $\mathbb{1}^{\text {ContractChange }}$ & $\mathbb{1}^{\text {ContractChange }}$ & $\mathbb{1}^{\text {ContractChange }}$ \\
\hline effcost & $\begin{array}{r}-1.472^{* *} \\
(0.751)\end{array}$ & $\begin{array}{c}-1.250^{*} \\
(0.731)\end{array}$ & & \\
\hline spread & & & $\begin{array}{r}-2.508^{* *} \\
(1.204)\end{array}$ & $\begin{array}{r}-2.487^{* *} \\
(1.206)\end{array}$ \\
\hline tvol & $\begin{array}{r}23.908 \\
(15.640)\end{array}$ & & $\begin{array}{r}14.911 \\
(14.443)\end{array}$ & \\
\hline ivol & & $\begin{array}{r}18.538 \\
(16.341)\end{array}$ & & $\begin{array}{r}13.443 \\
(15.440)\end{array}$ \\
\hline Size & $\begin{array}{r}0.050 \\
(0.071)\end{array}$ & $\begin{array}{r}0.044 \\
(0.070)\end{array}$ & $\begin{array}{r}-0.009 \\
(0.081)\end{array}$ & $\begin{array}{r}-0.014 \\
(0.080)\end{array}$ \\
\hline $\mathrm{Q}$ & $\begin{array}{r}0.065 \\
(0.074)\end{array}$ & $\begin{array}{r}0.062 \\
(0.074)\end{array}$ & $\begin{array}{r}0.031 \\
(0.077)\end{array}$ & $\begin{array}{r}0.028 \\
(0.077)\end{array}$ \\
\hline Leverage & $\begin{array}{r}-0.989^{* * *} \\
(0.379)\end{array}$ & $\begin{array}{r}-1.004^{* * *} \\
(0.379)\end{array}$ & $\begin{array}{r}-0.883^{* *} \\
(0.381)\end{array}$ & $\begin{array}{r}-0.891^{* *} \\
(0.382)\end{array}$ \\
\hline Dividend & $\begin{array}{r}-0.127 \\
(0.193)\end{array}$ & $\begin{array}{r}-0.151 \\
(0.192)\end{array}$ & $\begin{array}{r}-0.131 \\
(0.194)\end{array}$ & $\begin{array}{r}-0.143 \\
(0.192)\end{array}$ \\
\hline Age & $\begin{array}{r}0.015^{* * *} \\
(0.006)\end{array}$ & $\begin{array}{r}0.015^{* * *} \\
(0.006)\end{array}$ & $\begin{array}{r}0.017^{* * *} \\
(0.006)\end{array}$ & $\begin{array}{r}0.017^{* * *} \\
(0.006)\end{array}$ \\
\hline IOR & $\begin{array}{r}0.701 \\
(0.563)\end{array}$ & $\begin{array}{r}0.711 \\
(0.563)\end{array}$ & $\begin{array}{r}0.357 \\
(0.584)\end{array}$ & $\begin{array}{r}0.353 \\
(0.585)\end{array}$ \\
\hline Cash & $\begin{array}{r}3.440 \\
(3.776)\end{array}$ & $\begin{array}{r}3.449 \\
(3.775)\end{array}$ & $\begin{array}{r}3.032 \\
(3.790)\end{array}$ & $\begin{array}{r}3.032 \\
(3.791)\end{array}$ \\
\hline INV & $\begin{array}{r}0.153 \\
(0.638)\end{array}$ & $\begin{array}{r}0.163 \\
(0.642)\end{array}$ & $\begin{array}{r}0.205 \\
(0.636)\end{array}$ & $\begin{array}{r}0.200 \\
(0.640)\end{array}$ \\
\hline IOC & $\begin{array}{r}-1.332 \\
(1.065)\end{array}$ & $\begin{array}{r}-1.365 \\
(1.061)\end{array}$ & $\begin{array}{r}-0.977 \\
(1.088)\end{array}$ & $\begin{array}{c}-0.994 \\
(1.087)\end{array}$ \\
\hline Year Dummies & $\mathrm{Y}$ & $\mathrm{Y}$ & $\mathrm{Y}$ & $\mathrm{Y}$ \\
\hline Firm Dummies & $\mathrm{Y}$ & $\mathrm{Y}$ & $\mathrm{Y}$ & $\mathrm{Y}$ \\
\hline No. of Obs & 1247 & 1247 & 1247 & 1247 \\
\hline R-squared & 0.179 & 0.178 & 0.180 & 0.180 \\
\hline
\end{tabular}

where $\mathbb{1}_{i, t}^{\text {ContractChange }}$ is a dummy variable that equals one when firm $i$ announces changes in their CEO compensation policy in year $t$, and zero otherwise. fric $_{i, t}$ denotes firm $i$ 's trading frictions in year $t$, measured by effective trading cost (Hasbrouck (2009)) and bid-ask spread. For stock return volatility, we use both the total volatility ( $t v o l)$ and idiosyncratic volatility (ivol) described in Section 4.4. We use the same controls and firm-year fixed effects as our Equation (??) specification.

The results in Table 2 show that the two measures of trading frictions are significantly and negatively related to the likelihood of CEO contract changes: managers in firms with lower trading frictions may be more likely to learn from the market, and are more likely to experience compensation adjustments during Reg SHO. However, the coefficient of either total or idiosyncratic volatility is not significant. We find similar results using probit regressions. Although we do not draw causal inferences, it appears that pilot firms' decision to adopt compensation changes has a statistically strong relationship with firms' prior trading friction, which is in line with our managerial-learning mechanism, but not with their prior stock volatility. 
Table 3: The effects of decimalization on WPS

This table presents the effects of decimalization on WPS. $\mathbb{1}^{\text {Decimal }}$ is a dummy variable that equals one for 2001 through 2007 and zero for 1992 through 2000. $\mathbb{1}^{\text {HighTradingFriction }}$ is a dummy variable that equals one if the three-year (1998-2000) average of effective trading cost (Hasbrouck (2009)) is in the top tercile, and zero if it is in the bottom tercile. WPS measures the CEO pay-forperformance (Edmans et al. (2009)). Size is the logarithm of total assets. Q is the ratio of the market value of assets to the book value of assets, where the market value of assets is defined as the book value of assets (data 6) plus the market value of common equity (data 25 times data 199) less the book value of common equity (data 60) and balance sheet deferred taxes (data 74). Leverage is the sum of short-term debt (data 34) and long-term debt (data 9) divided by the sum of short-term and long-term debt and stockholders equity (data 216). Dividend is a dummy variable that equals one if a firm distributes dividends this year and zero otherwise. Age is calculated based on the first time when the firm's accounting information appeared in Compustat. IOR is the institutional investors' ownership ratio. Cash is the ratio of cash (data 126) divided by total assets (data 6). INV is the investment-to-capital ratio (INV), which is capital expenditure (data 128) divided by fixed assets (data 8). IOC measures the concentration of institutional ownership, which is the sum of the ownership ratio among the top five institutional investors. RetStd is the standard deviation of monthly stock returns. Standard errors are clustered at the firm level and reported in parentheses. ${ }^{*}, * *$, and ${ }^{* * *}$ represent statistical significance at the $10 \%, 5 \%$, and $1 \%$ levels, respectively.

\begin{tabular}{|c|c|c|c|c|}
\hline & (1) WPS & (2) WPS & (3) WPS & (4) WPS \\
\hline $\mathbb{1}^{\text {Decimal }}$ & $-0.195^{* * *}$ & $-0.092^{* *}$ & -0.052 & 0.028 \\
\hline & $(0.027)$ & $(0.039)$ & $(0.037)$ & $(0.057)$ \\
\hline \multirow[t]{2}{*}{$\mathbb{1}^{\text {Decimal }} \times \mathbb{1}^{\text {HighTradingFriction }}$} & & & $-0.285^{* * *}$ & $-0.204 * * *$ \\
\hline & & & $(0.074)$ & $(0.079)$ \\
\hline \multirow[t]{2}{*}{ Size } & & 0.017 & & 0.028 \\
\hline & & $(0.037)$ & & $(0.053)$ \\
\hline \multirow[t]{2}{*}{ Q } & & $0.057^{* * *}$ & & $0.054^{* * *}$ \\
\hline & & $(0.016)$ & & $(0.018)$ \\
\hline \multirow[t]{2}{*}{ Leverage } & & 0.001 & & 0.032 \\
\hline & & $(0.001)$ & & $(0.033)$ \\
\hline \multirow[t]{2}{*}{ Dividend } & & -0.062 & & -0.040 \\
\hline & & $(0.054)$ & & $(0.078)$ \\
\hline \multirow[t]{2}{*}{ Age } & & $-0.011^{* *}$ & & $-0.014^{*}$ \\
\hline & & $(0.005)$ & & $(0.007)$ \\
\hline \multirow[t]{2}{*}{ IOR } & & -0.143 & & -0.037 \\
\hline & & $(0.121)$ & & $(0.178)$ \\
\hline \multirow[t]{2}{*}{ Cash } & & 0.376 & & 0.500 \\
\hline & & $(0.293)$ & & $(0.327)$ \\
\hline \multirow[t]{2}{*}{ INV } & & 0.117 & & 0.109 \\
\hline & & $(0.100)$ & & $(0.124)$ \\
\hline \multirow[t]{2}{*}{$\mathrm{IOC}$} & & -0.039 & & -0.052 \\
\hline & & $(0.201)$ & & $(0.286)$ \\
\hline \multirow[t]{2}{*}{ RetStd } & & 0.304 & & 0.435 \\
\hline & & $(0.221)$ & & $(0.268)$ \\
\hline Firm Dummies & Y & Y & $\mathrm{Y}$ & $\mathrm{Y}$ \\
\hline No. of Obs & 25,647 & 20,333 & 13,548 & 11,091 \\
\hline R-squared & 0.606 & 0.625 & 0.625 & 0.651 \\
\hline
\end{tabular}

\section{F.2 Alternative identification strategy I: Decimalization}

To provide further empirical evaluation of our argument, we adopt two alternative identification strategies in the next subsections. The first is decimalization, also regulatory change in the U.S. stock market that proxies for an exogenous reduction in market frictions. Decimalization occurred when U.S. stock markets reduced the minimum tick size from 1/16 dollar to one cent in 2001. Empirical research shows that it is effective in reducing bid-ask spreads (e.g., Furfine (2003) and Bessembinder (2003)). Using decimalization as another exogenous shock to market frictions, we regress WPS on a decimalization dummy variable, $\mathbb{1}^{\text {Decimal }}$, which equals one for 2001 through 2007 and zero for 1992 through 2000, with the same control variables as in Equation (??). We include all firms that have WPS data available. In Columns (1) and (2) of Table 3, we show that the coefficient of $\mathbb{1}^{\text {Decimal }}$ is negative and significant.

One might be concerned that this reflects merely a time trend in CEO compensation. To address this issue, we employ a difference-in-difference methodology: As firms with high trading 
friction pre-decimalization should benefit most from decimalization, we expect the compensation response to be concentrated in these firms. Specifically, we sort firms based on trading friction, proxied by the three-year average effective trading cost (Hasbrouck (2009)), into tercile groups (high, median, and low effective cost of trading). We re-run our regression with the decimalization dummy and a dummy that equals one when a firm's pre-decimalization trading friction is in the top tercile and zero if it is in the bottom tercile. Columns (3) and (4) of Table 3 show that the interaction term of the decimalization dummy and the high-trading-friction dummy is significantly negative, while the effect of decimalization on the low-trading-friction group is not significant. The result is consistent with the idea that the reduction of CEO pay-for-performance is concentrated in firms with high pre-decimalization trading friction, as the reduction of trading friction should be most effective for these firms.

\section{F.3 Alternative identification strategy II: Russell indexing}

Our second alternative identification strategy utilizes a regression discontinuity design based on Russell 1000/2000 indexing. Based on the end-of-May market capitalization each year, stocks are assigned to the Russell 1000 (the largest 1000) and the Russell 2000 (the 1001st through the 3000th) indices. As institutional assets are benchmarked to both indices and the indices are value-weighted, stocks just below the 1,000 threshold (those in the very top of the Russell 2000 index) receive significantly more forced buying by passive stock index funds and by many active institutional investors who are benchmarked to these indices, whereas stocks just above the threshold (those at the very bottom of the Russell 1000 index) have almost none. Firm characteristics are similar around the 1000 cutoff, but institutional ownership and stock liquidity have a discontinuous jump around the threshold due to a shift of index weights and hence a shift of benchmarking money, documented in Cheng, Hong, and Liskovich (2015) and Boone and White (2015). ${ }^{3}$ Private information is more likely to get generated and incorporated into the price due to discontinuously greater liquidity, and empirical research confirms this effect on the information environment (Boone and White (2015)). Using this plausibly exogenous variation in trading friction, we expect the firms just below the 1000 cutoff (those in the very top of the Russell 2000 index) to have a lower WPS than those just above the cutoff (those at the very bottom of the Russell 1000 index), as increased institutional buying and liquidity make trading less frictional for these stocks just below the cutoff.

We employ a local linear regression that focuses on $\mathrm{N}$ (bandwidth) stocks at the bottom of the Russell 1000 index and N stocks at the top of the Russell 2000 index. ${ }^{4}$ We choose N to be

\footnotetext{
${ }^{3}$ We perform a series of validity tests to show that firm characteristics are continuous around the threshold, a result also reported in Cheng, Hong, and Liskovich (2015) and Boone and White (2015).

${ }^{4}$ See Hahn, Todd, and van der Klaauw (2001) and Lee and Lemieux (2010) for a detailed discussion of the advantage of using a local linear regression.
} 
Table 4: The effects of Russell 1000/2000 indexing on WPS

This table presents the effects of Russell 1000/2000 indexing on WPS by using a local linear regression. $\mathbb{1}^{\text {Russell2000Top is a dummy }}$ variable that equals one when a stock is in the top $\mathrm{N}$ (bandwidth) firms of the Russell 2000 index, and zero when in the bottom $\mathrm{N}$ of the Russell 1000 index. N ranges from 100 to 250 in columns (1) to (8). WPS measures the CEO pay-for-performance (Edmans et al. (2009)). Size is the logarithm of total asset. Q is the ratio of the market value of assets to the book value of assets, where the market value of assets is defined as the book value of assets (data 6) plus the market value of common equity (data 25 times data 199) less the book value of common equity (data 60) and balance sheet deferred taxes (data 74). Leverage is the sum of short-term debt (data 34) and long-term debt (data 9) divided by the sum of short-term and long-term debt and stockholders equity (data 216). Dividend is a dummy variable equal to one if a firm distributes dividends this year and zero otherwise. Age is calculated based on the first time when the firm's accounting information appeared in Compustat. IOR is the institutional investors' ownership ratio. Cash is the ratio of cash (data 126) divided by total assets (data 6). INV is the investment-to-capital ratio (INV), which is capital expenditure (data 128) divided by fixed assets (data 8). IOC measures the concentration of institutional ownership, which is the sum of the ownership ratio among the top five institutional investors. RetStd is the standard deviation of monthly stock returns. Standard errors are clustered at the firm level and reported in parentheses. ${ }^{*}, * *$, and $* * *$ represent statistical significance at the $10 \%, 5 \%$, and $1 \%$ levels, respectively.

\begin{tabular}{|c|c|c|c|c|c|c|c|c|}
\hline & (1) WPS & (2) WPS & (3) WPS & (4) WPS & (5) WPS & (6) WPS & (7) WPS & (8) WPS \\
\hline $\mathbb{1}^{\text {Russell } 2000 T o p}$ & $\begin{array}{r}-0.649^{* * *} \\
(0.196)\end{array}$ & $\begin{array}{r}-0.593^{* * *} \\
(0.219)\end{array}$ & $\begin{array}{r}-0.460^{* * *} \\
(0.133)\end{array}$ & $\begin{array}{r}-0.395^{* * *} \\
(0.141)\end{array}$ & $\begin{array}{r}-0.335^{* * *} \\
(0.095)\end{array}$ & $\begin{array}{r}-0.331^{* * *} \\
(0.107)\end{array}$ & $\begin{array}{r}-0.257^{* * *} \\
(0.073)\end{array}$ & $\begin{array}{r}-0.292^{* * *} \\
(0.088)\end{array}$ \\
\hline \multirow[t]{2}{*}{ Size } & & $-0.188^{* *}$ & & $-0.177^{* *}$ & & $-0.167^{* * *}$ & & $-0.135^{* * *}$ \\
\hline & & $(0.093)$ & & $(0.078)$ & & $(0.062)$ & & $(0.052)$ \\
\hline \multirow[t]{2}{*}{$\mathrm{Q}$} & & 0.121 & & $0.105^{*}$ & & $0.090^{*}$ & & $0.092^{* *}$ \\
\hline & & $(0.075)$ & & $(0.063)$ & & $(0.050)$ & & $(0.046)$ \\
\hline \multirow[t]{2}{*}{ Leverage } & & -0.001 & & -0.004 & & 0.001 & & 0.002 \\
\hline & & $(0.007)$ & & $(0.005)$ & & $(0.004)$ & & $(0.004)$ \\
\hline \multirow[t]{2}{*}{ Dividend } & & -0.167 & & -0.042 & & -0.026 & & -0.025 \\
\hline & & $(0.136)$ & & $(0.113)$ & & $(0.099)$ & & $(0.077)$ \\
\hline \multirow[t]{2}{*}{ Age } & & $-0.011^{* *}$ & & $-0.010^{* * *}$ & & $-0.010^{* * *}$ & & $-0.009^{* * *}$ \\
\hline & & $(0.005)$ & & $(0.004)$ & & $(0.003)$ & & $(0.003)$ \\
\hline \multirow[t]{2}{*}{ IOR } & & $-1.652^{* * *}$ & & $-1.726^{* * *}$ & & $-1.625^{* * *}$ & & $-1.410^{* * *}$ \\
\hline & & $(0.530)$ & & $(0.470)$ & & $(0.372)$ & & (0.309) \\
\hline \multirow[t]{2}{*}{ Cash } & & -0.150 & & -0.985 & & 1.122 & & 1.487 \\
\hline & & (2.999) & & $(1.926)$ & & $(1.732)$ & & $(1.383)$ \\
\hline \multirow[t]{2}{*}{ INV } & & -0.663 & & -0.237 & & -0.178 & & -0.200 \\
\hline & & $(0.504)$ & & $(0.378)$ & & $(0.289)$ & & $(0.232)$ \\
\hline \multirow[t]{2}{*}{ IOC } & & 0.969 & & $1.096^{* *}$ & & $1.137^{* *}$ & & $0.966^{* * *}$ \\
\hline & & $(0.622)$ & & $(0.554)$ & & $(0.446)$ & & $(0.365)$ \\
\hline \multirow[t]{2}{*}{ RetStd } & & -0.508 & & -0.138 & & -0.166 & & -0.163 \\
\hline & & $(1.058)$ & & $(0.911)$ & & $(0.795)$ & & $(0.584)$ \\
\hline Bandwidth & 100 & 100 & 150 & 150 & 200 & 200 & 250 & 250 \\
\hline Year Dummies & Y & Y & Y & Y & Y & Y & $\mathrm{Y}$ & $\mathrm{Y}$ \\
\hline No. of Obs & 946 & 763 & 1556 & 1270 & 2195 & 1779 & 2806 & 2272 \\
\hline $\mathrm{R}$-squared & 0.037 & 0.138 & 0.023 & 0.123 & 0.015 & 0.115 & 0.011 & 0.105 \\
\hline
\end{tabular}

100, 150, 200, and 250 as these bandwidths balance the efficiency of employing larger sample sizes against the bias of including firms further from the threshold that could have increasingly disparate firm characteristics. Specifically, we regress WPS on a dummy variable, which equals one when a stock is in the top $\mathrm{N}$ firms of the Russell 2000 index, and zero when in the bottom $\mathrm{N}$ of the Russell 1000 index, together with control variables. Table 4 shows that the coefficients of this dummy variable are significantly negative for all bandwidth choices, consistent with the idea that firms at the top of the Russell 2000 index, shown to be subject to less trading friction (Boone and White, 2015), have significantly lower WPS than firms at the bottom of the Russell 1000 index. $^{5}$

\footnotetext{
${ }^{5}$ We also estimate the treatment effect of Russell 1000/2000 indexing by fitting a local third-order polynomial estimate using a triangular kernel to the left and right of the index cutoff based on the bias-correction methodology in Calonico, Cattaneo, and Titiunik (2015). Following Calonico, Cattaneo, and Titiunik (2014) to estimate the rule of thumb bandwidth, we find significantly negative treatment coefficients.
} 


\section{F.4 Discussion of empirical findings}

Our results highlight a contrast with the existing literature, which documents a positive association between managerial pay-for-performance and stock price informativeness and argues that more informative stock prices enhance the link between managerial pay and firm performance. ${ }^{6}$ Using regulatory changes to circumvent potential endogeneity issues, we show that the degree of pay-for-performance can actually be substituted out by information provision in the financial market.

Taken together, our empirical analysis using these experiments provides confirming evidence that changes in the stock market environment affect the design of managerial compensation, and this set of results collectively point to the feedback effect as a natural, coherent explanation. A review of alternative theories on the role of financial markets for compensation design reveals the difficulty in consistently producing the data patterns we document. For example, the risk-sharing consideration in Holmstrom and Milgrom (1987) can lower incentives when faced with increased downside risk for pilot firms during Reg SHO. However, Diether, Lee, and Werner (2009) find that pilot stocks' returns and volatility are not affected. In addition, Hong and Stein (2003) argue that stock price crash risk would decrease when short-sale constraints are relaxed. Deng, Gao, and Kim (2016) show that crash risk is reduced in pilot firms during the Reg SHO Pilot program. The risk-insurance tradeoff also has limited relevance for decimalization or Russell 1000/2000 indexing. The monitoring role of stock markets highlighted in Holmstrom and Tirole (1993) suggests that equity compensation is more effective in offering incentives when stock prices incorporate more information about managerial actions, predicting a complementary relationship between incentive pay and market informativeness, which is the opposite of what we find in the data. Similarly, the governance mechanism based on "voting with feet" would in theory render the use of equity compensation more necessary to make blockholders' threat of exit relevant for managers, and it empirically requires the presence of blockholders to take effect. ${ }^{7}$ In sum, the set of results we find in the data are most consistent with our theory of the feedback effect.

\section{References}

Baker M, Stein J.C., Wurgler J. 2003. When does the market matter? Stock prices and the investment of equity-dependent firms. Quarterly Journal of Economics, 118(3), 969-1006.

Bakke TE, Whited T. M., 2010. Which firms follow the market? An analysis of corporate investment decisions. Review of Financial Studies, 23(5), 1941-1980.

\footnotetext{
${ }^{6}$ See Kang and Liu (2008) and Kang and Liu (2010), for example. Similarly, Jayaraman and Milbourn (2012) show that the CEOs' pay-for-performance sensitivity with respect to stock prices is increasing in the liquidity of the stock.

${ }^{7}$ Recent empirical studies also show that the external governance mechanism would work better at firms with higher incentive pay (for example, Bharath, Jayaraman and Nagar (2013) and Edmans, Fang, and Zur (2013)).
} 
Bertrand, M., and Mullainathan, S. 2003. Enjoying the quiet life? Corporate governance and managerial preferences. Journal of Political Economy, 111(5), 1043-1075.

Bessembinder, H. 2003. Trade execution costs and market quality after decimalization. Journal of Financial and Quantitative Analysis, 38(4), 747-777.

Boone, A.L. and White, J.T., 2015. The effect of institutional ownership on firm transparency and information production, Journal of Financial Economics, 117(3), 508-533.

Calonico, S., Cattaneo, M. D., and Titiunik, R. 2014. Robust nonparametric confidence intervals for regression-discontinuity designs. Econometrica, 82(6), 22952326.

Calonico, S., Cattaneo, M. D., and Titiunik, R. 2015. Optimal data-driven regression discontinuity plots. Journal of the American Statistical Association, 110(512), 17531769.

Chang, Y.C., Hong, H. and Liskovich, I., 2015. Regression discontinuity and the price effects of stock market indexing. Review of Financial Studies, 28(1), 212-246

Edmans, A., Goldstein, I., and Jiang, W. 2012. The real effects of financial markets: The impact of prices on takeovers. Journal of Finance, 67, 933-971.

Edmans, A., Goldstein, I., and Jiang, W. 2015. Feedback effects, asymmetric trading, and the limits to arbitrage. American Economic Review, 105, 3766-3797.

Foucault, T. and Gehrig, T., 2008. Stock price informativeness, cross-listings, and investment decisions. Journal of Financial Economics, 88(1), 146-168.

Fishman, M.J. and Hagerty, K.M., 1992. Insider trading and the efficiency of stock prices. RAND Journal of Economics, 106-122

Fulghieri, P. and Lukin, D., 2001. Information production, dilution costs, and optimal security design. Journal of Financial Economics, 61(1), 3-42.

Furfine, C. H. 2003. Decimalization and market liquidity. Economic Perspectives. 27(4), 2-12.

Gao, P. and Liang, P.J., 2013. Informational feedback, adverse selection, and optimal disclosure policy. Journal of Accounting Research, 51(5), 1133-1158.

Gorton, G.B., Huang, L. and Kang, Q., 2016. The limitations of stock market efficiency: price informativeness and CEO turnover. Review of Finance, 21, 153-200.

Hahn, J., Todd, P. and Van der Klaauw, W., 2001. Identification and estimation of treatment effects with a regression discontinuity design. Econometrica, 69(1), pp.201-209.

Hasbrouck, J., 2009. Trading costs and returns for US equities: Estimating effective costs from daily data. Journal of Finance, 64(3), 1445-1477.

Hayek, F. A. (1945). The use of knowledge in society. American economic review, 519-530.

Hicks, J. R. 1935. Annual survey of economic theory: the theory of monopoly. Econometrica 3,120 .

Kang, Q., Liu, Q. 2008. Stock trading, information production, and executive incentives. Journal of Corporate Finance, 14(4), 484-498. 
Kang, Q., Liu, Q. 2010. Information-based stock trading, executive incentives, and the principal-agent problem. Management Science, 56(4), 682-698.

Khanna, N., Slezak, S.L. and Bradley, M., 1994. Insider trading, outside search, and resource allocation: why firms and society may disagree on insider trading restrictions. Review of Financial Studies, 7(3), 575-608.

Lee, D.S. and Lemieuxa, T., 2010. Regression discontinuity designs in economics. Journal of Economic Literature, 48(2), 281-355.

Luo Y. 2005. Do insiders learn from outsiders? Evidence from mergers and acquisitions. Journal of Finance, 60(4), 1951-1982.

Subrahmanyam, A. and Titman, S., 1999. The going public decision and the development of financial markets. Journal of Finance, 54(3), 1045-1082. 